\title{
Mapping of Sabah Islands using Airborne Hyperspectrometer
}

\author{
Hj. Kamaruzaman Jusoff \\ Yale University, Center for Earth Observation, Environmental Science Center \\ 21 Sachem St, New Haven, CT 06511, USA \\ Tel: 1-203-432-1384 E-mail: jusoff.kamaruzaman@yale.edu
}

This project is funded by Aeroscan Precision (M) and TERAS Tech (M) Sdn Bhd

\begin{abstract}
Human recreational activities and tourism are concentrated on the islands and in coastal waters, often depending on the maintenance of high water quality. The managing of impacts of urbanization and industrialization on the coastal zone ecology has become a high priority for many nations such as Malaysia and, hence, the need to develop better methods for monitoring and predicting change in islands and their coastal systems. Many of the dynamics of the open ocean, islands and changes in their coastal areas can be mapped and monitored using remote sensing techniques. Hyperspectral imaging is a tool that can provide an increasing number of marine and coastal properties over a spatial and temporal range. The remote-sensing measurements of some selected Sabah islands and their coastal waters were collected using a $4 \mathrm{~kg}$ "bread-box" sized UPM-APSB's AISA (Airborne Imaging Spectroradiometer for different Applications) airborne spectrographic imager where it was flown over the islands of Bohey, Mabul, Pom-Pom, Kulapuan, Omadal and Larapan study areas as part of the 2004 Sabah's "Ops Pasir" inaugural flight experiment in Sabah on July 13, 2004. The purpose of the study was to determine the current capabilities of a locally developed UPM-APSB's AISA airborne hyperspectral remote sensing applications to operationally map and monitor the islands in Sabah and observe the status of their coastal waters and reef environment. The airborne data were pre-processed on-board a fixed wing aircraft and later processed using spectral end member during the advance digital processing techniques. AISA AeroMAP ${ }^{\mathrm{TM}}$ research products showed that the current technology did a good job of conveying spatial variability of the parameters being tested such as human activities and impact, presence of fishing boats, coral reef, near shore shallow bathymetry, shoreline features and coastal vegetation.
\end{abstract}

\section{Introduction}

The monitoring and maintenance of water quality and ecological quality of islands, coastal zones and inland waters is a growing national concern. Over $20 \%$ of the Malaysian human population, especially in Sabah lives in the shallow waters zone surrounding the islands. Coastal development can lead to modification of foreshores, loss of key habitats, changes to flushing rates, re-suspension of sediments, and direct inputs of nutrients and toxicants. Coastal waters are of particular significance in terms of the national fishery. Human recreational activities and tourism are concentrated on the island and her coastal waters and often depend on the maintenance of high water quality. The managing of impacts of urbanization and industrialization on the 
coastal zone ecology has become a high priority for many states in Malaysia and, hence, the need to develop better methods for monitoring and predicting change on the islands and her coastal systems.

Recently, UPM-Aeroscan Precision (M) Sdn Bhd has begun utilizing this approach with airborne hyperspectral data of the near-shore marine environment. While ocean data are generally more complex, and some work has been done in applying hyperspectral sensing data to near-shore-marine problems (Holden and LeDrew, 1999; Holden et al., 1999; Hochberg and Atkinson, 2000), many of the concepts developed for forestry and agricultural analysis are applicable to analysis of near-shore airborne hyperspectral data. The UPM-APSB's AISA airborne hypespectral imaging case study described here for some selected Sabah Islands, utilizes the unique capabilities of airborne hyperspectral data to locate, map, and identify components of the beautiful coral reef ecosystem, assessing airborne hyperspectral data's capability with respect to little established ground truth. The overall aim of this paper is the development of a monitoring system for island and coral reef database ecosystems based on hyperspectral remote sensing information. This monitoring system should enable not only the efficient mapping of the coral reefs surrounding the beautiful islands, but also the identification of the reefs that are most endangered. This information will significantly contribute to the progress of protecting and restoring the coral reef and island environments and will in this way add to the sustainable development of these valuable natural resources.

\section{Methods}

\subsection{Description of study site}

A mission was undertaken over the waters of some selected Sabah Islands to examine the effort required to examine and map the coral reef habitat conditions around the Islands (Figures 1a and 1b). The majority of the effort took place over the Islands of Bohey, Mabul, Pom-Pom, Kulapuan, Omadal and Larapan, during the months of July 2004. These selected islands are excellent test case areas due to their distribution of both fringing and platform reef morphologies and the existence of protected reef habitat.

\section{$<<$ Fig. 1a. A map of the selected islands in Sabah $>>$}

\section{$<<$ Fig. 1b. A map of Sabah with selected islands in dotted circle $>>$}

\subsection{The test data and sensor system}

A UPM-APSB's AISA sensor deployed on a Sabah Air's GAF N22B aircraft was acquired over the selected Sabah Islands on $13^{\text {th }}$. July 2004. The UPM-APSB's AISA instrument was programmed in its mode 2 setting, which has a 20 band spectral resolution and a full spatial resolution of $1 \mathrm{~m}$ at nadir in the visible and near-infrared part of the spectrum.

\subsection{Data processing and image analysis}

UPM-APSB has evolved a "standardized" airborne hyperspectral data analysis methodology that has been tested for a variety of data. within the "Environment for Visualizing Images" (ENVI) software system. This is not the only way to analyze these data, but it has been found that it provides a consistent way to extract spectral information from airborne hyperspectral data without a priori knowledge or requiring ground observations. The analysis approach consists of (a) correction for atmospheric effects, (b) spectral compression, noise suppression, and dimensionality reduction using the Minimum Noise Fraction (MNF) transformation, (c) determination of end-members using geometric methods (Pixel Purity Index - "PPI"), (d) extraction of end-member spectra using n-dimensional scatter plotting, (e) identification of end-member spectra using visual inspection, automated identification, and spectral library comparisons, and (f) production of some selected Sabah Islands maps using a variety of mapping methods. 


\section{Results and discussion}

The airborne hyperspectral technology may provide accurate base maps distribution of the reef communities, coastline features, mainland activities and allows for change detection in near real time. It is quite evident that the detected shoreline features are differentially but consistently offset from one another indicates that a range of physical characteristics in the vicinity of the land-water interface are being detected. It is reasonable to speculate that a number of factors could potentially influence the position of shoreline indicator or features obtained by digital image analysis. The land-water-coral discrimination can be clearly extracted from the image where water is shown in blue, mainland in orange and green, human activities in purple and bright patches while the corals are in darker blue-green and dark purple colors, surrounding Mabul and Omadal Islands, respectively (Figs.2 and 3).

\section{$<<$ Fig. 2. The corals around Mabul Island $>>$}

\section{$<<$ Fig. 3. Coconut plantations on Omadal Island $>>$}

The islands are also characterized by shallow and gentle sloping sea bottom, and seem to be protected by any monsoon during the image acquisition time. The existence of healthy coral reefs in the area proves that those islands under study provide favorable conditions for coral reefs to develop. At Kulapuan and Pom-Pom Islands survey sites for instance, the reefs are in good shape with high live coral cover ranging from $40-60 \%$ (Figs. 4 and 5). The same benthic type, for example sandy bottom in both islands, can be interpreted as shallow, moderately deep and deep sand. At a similar water depth, the reflectance of reefs and seagrass beds recorded in visible bands $(400-700 \mathrm{~nm})$ is generally lower than from a sandy bottom. Reefs and seagrass beds behave as darker blue features in contrast to the brighter white sandy coastlines (Figs. 6and 7). At the land/seascape ecological scale, there are interconnections between coral reef, seagrass ecosystems, and the upland land use/land cover. Coral reef communities are highly adapted to nutrient-deficient, oligotrophic and clear water conditions. They often depend upon other ecosystems such as coastal forest, mangrove wetlands and sea-grass beds, which normally act as filters for sediment run-off from land. The suspended silt decreases light penetration, thus reducing photosynthesis and diminishing the principle nutritional source for the corals.

\section{$<<$ Fig. 4. The "untouched" Kulapuan Island $>>$}

\section{$<<$ Fig. 5. Pom-pom Island rich with benthic cover $>>$}

The development in some of the islands especially Larapan and Bohey Dulang Islands coupled with an increasing population means more land clearance for construction and agricultural land use (Figs. 7 and 8). This will potentially lead to increased runoff and excessive sedimentation and subsequently end up on coastal water where fringing coral reefs scattered along the coastlines. The knowledge of the areas more vulnerable to erosion could be of use to resource managers in proper land use planning for the sake of the nearby coral reef viability.

\section{$<<$ Fig. 6. Larapan Island rich with coral habitat $>>$}

\section{$<<$ Fig.7. Bohey Dulang Island with human activities $>>$}

\section{Conclusions}

These analyses show that the near real time UPM-APSB's AISA airborne hyperspectral separation and mapping of distinct land/water, near-shore bottom characteristics and human activities surrounding and on the islands are possible. UPM-APSB data were used to demonstrate the capability of airborne hyperspectral remote sensing for a quick and effective monitoring of remote coral reef regions, such as those surrounding the selected islands in Sabah's coastal waters. While there is some potentials of these basic UPM-APSB results to publish benthic habitat maps, coral reef distribution, coastline features, near-shore bathymetry and human activities, depth dependencies are apparent. Spectral "ground truth" at UPM-APSB's AISA scales is required for verification of similarities/differences. 


\section{References}

Hochberg, E. J., and M.J. Atkinson. (2000). Spectral discrimination of coral reef benthic communities: Coral Reefs. 19, $164-171$.

Holden, H., Kalbfleisch, W., Neman, C., and LeDrew, E. (1999). Hyperspectral identification of coral reef features: Proceedings of the Fourth International Airborne Remote Sensing Conference and Exhibition/ $21^{\text {st }}$ Canadian Symposium on Remote Sensing, Ontario, Canada, p. I-129 - I-136.

Holden, H. and E. LeDrew. (1999). Hyperspectral identification of coral reef features: International Journal of Remote Sensing, 20 (13), 2545 - 2563.

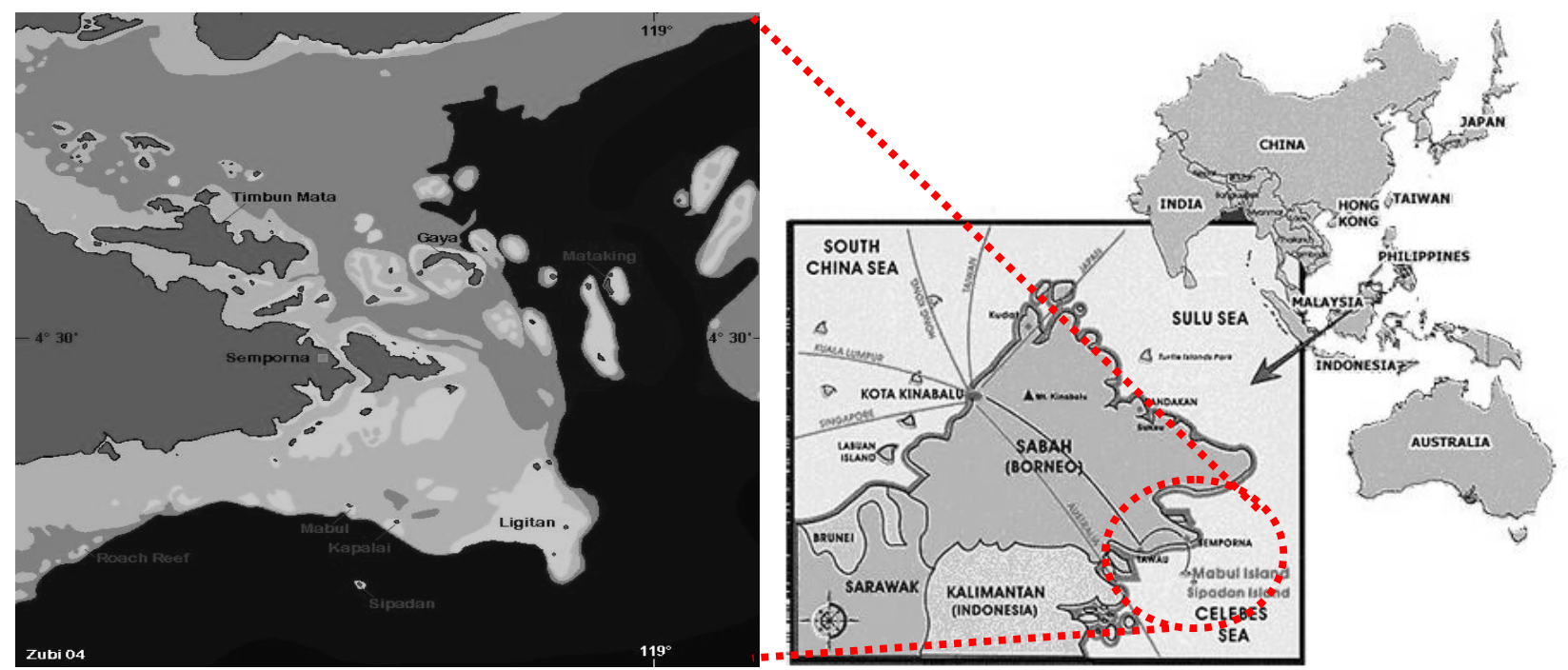

Figure 1a. A map of the selected islands in Sabah

Figure 1b. A map of Sabah with selected islands in dotted circle

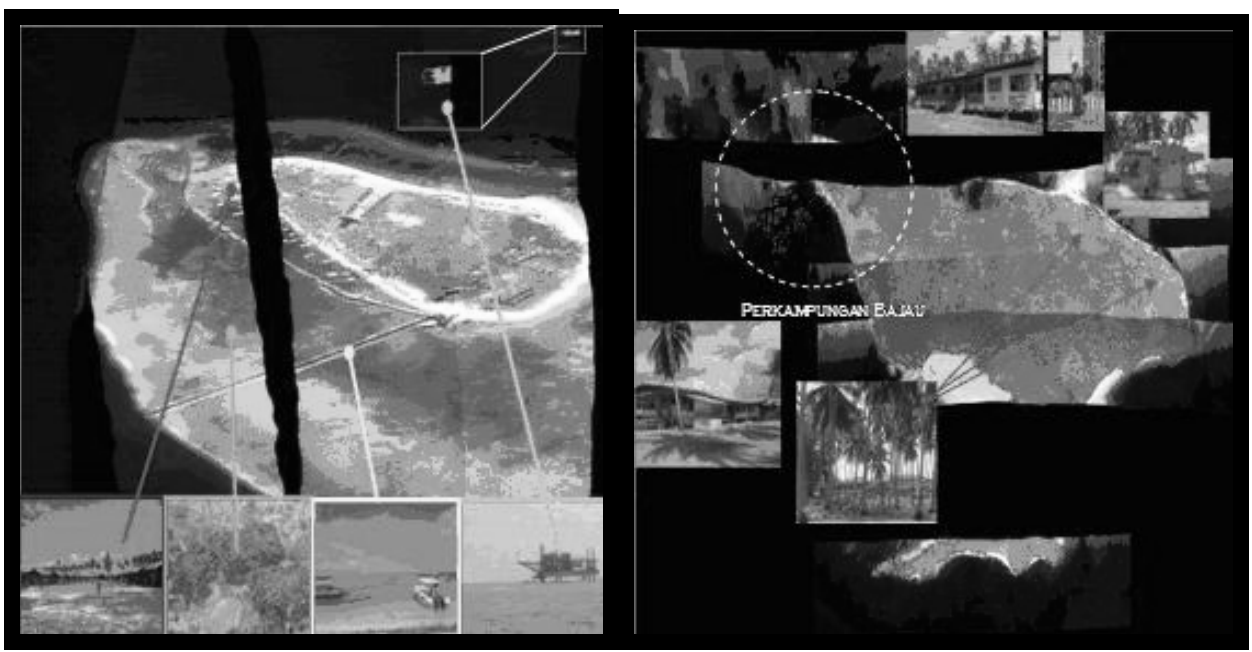

Figure 2. The corals around Mabul Island

Figure 3. Coconut plantations on Omadal Island 


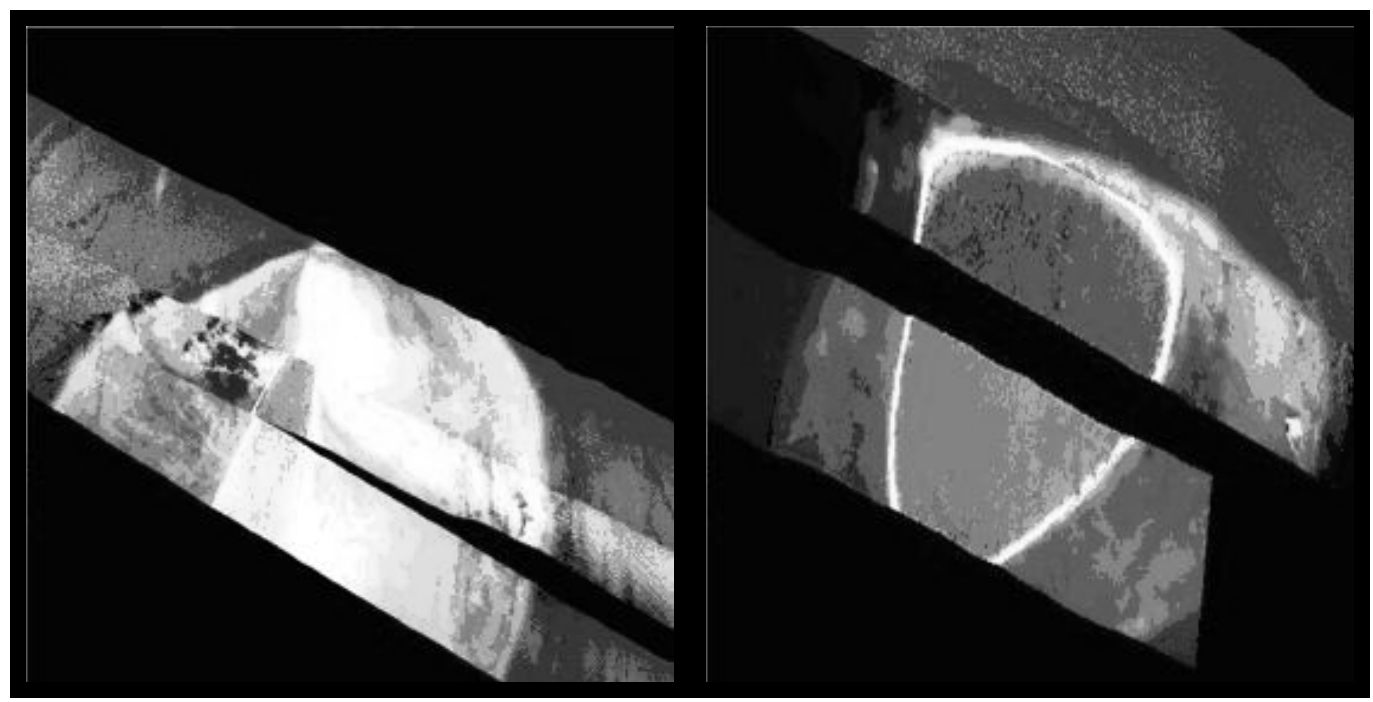

Figure 4. The "untouched" Kulapuan Island

Figure 5. Pom-pom Island rich with benthic cover

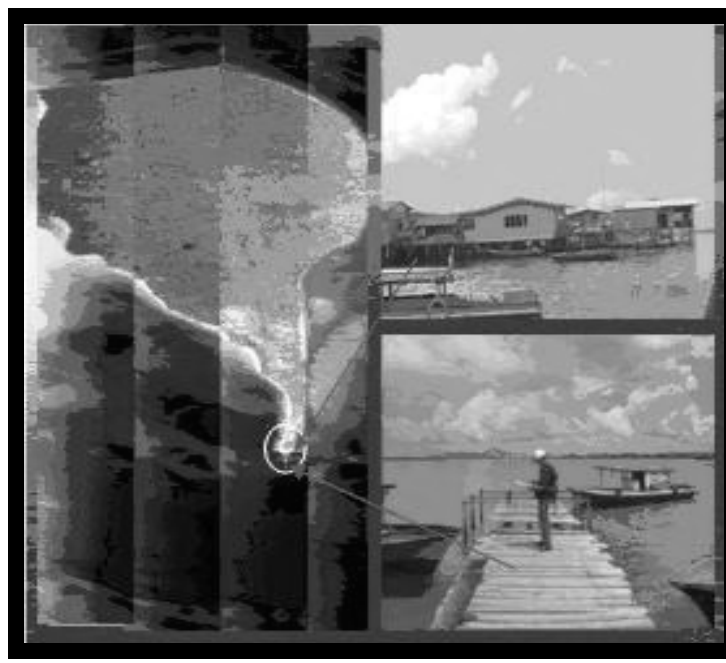

Figure 6. Larapan Island rich with coral habitat activities

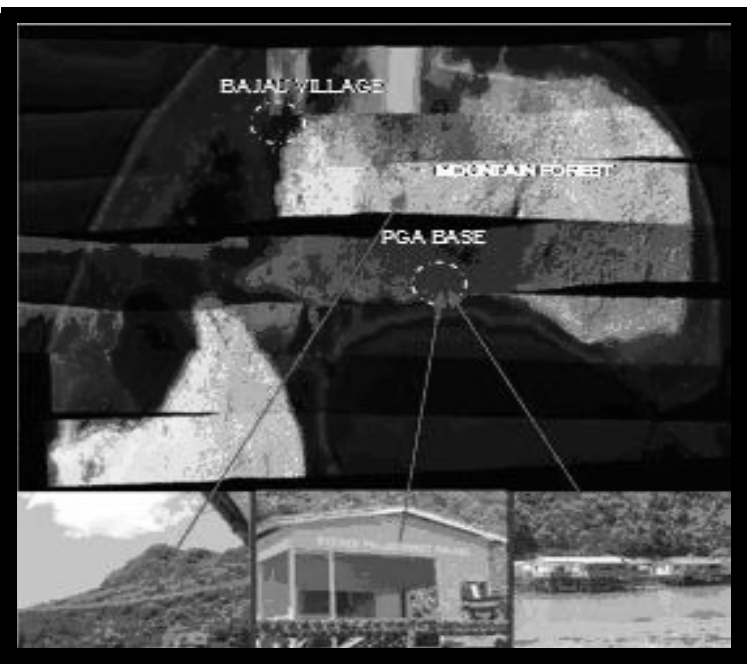

Figure 7. Bohey Dulang Island with human 